\title{
CRESCIMENTO DE ARUNDINA GRAMINIFOLIA (D. DON.) HOCHR. EM DIFERENTES MEIOS DE CULTIVO E NIVEIS DE pH
}

\author{
Cristiano Pedroso-de-Moraes* \\ Thiago Souza-Leal ${ }^{* *}$ \\ José Alberto Diogo **** \\ Rosangela Isete Canabrava** \\ Natália Pierobon Pedro**** \\ Marco Aurélio Marteline ${ }^{* * * * * *}$
}

RESUMO: Arundina graminifolia é uma orquídea apreciada mundialmente pelo seu valor ornamental, possuindo também uso medicinal. Entretanto, os baixos investimentos relacionados a melhorias das atuais técnicas de cultivo in vitro, ferramenta importante para propagação de diversas espécies de orquídeas, impedem a diminuição dos custos de propagação. O presente trabalho teve por objetivo avaliar os efeitos do meio de cultura $1 / 2 \mathrm{MS}$ e de dois meios a base dos fertilizantes comerciais Hyponex ${ }^{\circledR}$ (NPK 6,5-6-19) e Kristalon laranja ${ }^{\circledR}$ (NPK 6-12-36), submetidos a três níveis de $\mathrm{pH}(5,3,5,8$ e 6,3), sobre o crescimento in vitro de $A$. graminifolia. Para tanto, sementes foram distribuídas em quatro frascos de cada meio e, após 180 dias de cultivo, foram retiradas aleatoriamente vinte plântulas de cada frasco para análise estatística. $\mathrm{O}$ meio de cultura mais eficiente foi o meio $1 \frac{1}{2} \mathrm{MS}$ com nível de $\mathrm{pH}$ de 5,8, que apresentou as maiores médias para todas as variáveis analisadas.

PALAVRAS-CHAVE: Arundina bambusifolia; Orchidaceae; Orquídea bambu; Propagação in vitro.

\section{GROWTH OF ARUNDINA GRAMINIFOLIA (D. DON.) HOCHR. IN DIFFERENT CULTURE MEDIA WITH DIFFERENT pH LEVELS}

ABSTRACT: Arundina graminifolia is an orchid, widely appreciated for its beauty,

\footnotetext{
Doutor em Biologia Vegetal; Docente no Centro Universitário Hermínio Ometto (UNIARARAS), Araras (SP), Brasil; E-mail: pedroso@uniararas.b

** Mestre em Ciências Biológicas pela Universidade Estadual Paulista Júlio de Mesquita Filho (UNESP) Rio Claro (SP), Brasil

${ }^{* * *}$ Mestre em Ciência de Alimentos pela Universidade Estadual de Campinas (UNICAMP) Brasil

**** Alunos de Iniciação Científica do Lab. de Botânica e Análises Ambientais do Centro Universitário Herminio Ometto (UNIARARAS), Araras (SP), Brasil.

${ }^{* * * * *}$ Doutor em Ciências Biológicas pela Universidade Estadual Paulista Júlio de Mesquita Filho (UNESP); Docente no Departamento de Biotecnologia da Universidade Federal de São Carlos (UFSCAR), Brasil.
} 
also used as medicine. Low investments in the improvement of current in vitro culture techniques, an important tool for the propagation of species of orchids, impairs decrease in costs. Current analysis assesses the effects of culture medium $1 / 2$ MS and two media based on commercial fertilizers Hyponex ${ }^{\circledR}$ (NPK 6.5-6-19) and Kristalon orange ${ }^{\circledR}$ (NPK 6-12-36), at three $\mathrm{pH}$ levels (5.3, 5.8 and 6.3), on the in vitro growth of A. graminifolia. Seeds were placed in four flasks with each medium and 20 seedlings were removed randomly after 180 days of culture from each flask, for statistical analysis. The most efficient culture medium was $1 / 2 \mathrm{MS}$ at $\mathrm{pH}$ level 5.8, with the greatest media for all variables analyzed.

KEY WORDS: Arundina bambusifolia; Orchidaceae; Bamboo orchid; In vitro propagation.

\section{INTRODUÇÃO}

Entre as espécies ornamentais e medicinais comercializadas, as orquídeas se destacam, principalmente, no oriente. Contudo, tais plantas apresentam alto custo de produção (PEDROSO-DE-MORAES et al., 2011), principalmente devido aos baixos investimentos relacionados a melhorias das atuais técnicas de cultivo in vitro e ex vitro, que propiciem aumento de velocidade e redução de custos de propagação (PEDROSO-DE-MORAES et al., 2009a).

Arundina graminifolia (D. Don) Hochr constitui uma das espécies de orquídeas terrestres utilizada na medicina tradicional oriental (SIGH; DUGGAL, 2009) e, ornamentalmente, apresenta destaque no agronegócio florícola nacional e mundial como planta de jardim, devido a características intrínsecas à espécie, tais como beleza, resistência a altas intensidades luminosas e tamanho de flores e partes vegetativas (LORENZI; SOUZA, 1999).

Conhecida popularmente como orquídea-bambu, A. graminifolia é originária da Ásia Tropical desde a Índia, Nepal, Tailândia, Malásia, Singapura, China Setentrional, Indonésia às Ilhas do Pacífico, onde é utilizada como bactericida e cicatrizante tópico e estomacal (SIGH; DUGGAL, 2009; MEDHI; CHAKRABARTI, 2009; ACHARYA; ROKAYA, 2010). Nos neotrópicos, foi primeiramente introduzida em Porto Rico, Costa Rica e Panamá, de onde se irradiou para os demais países 
latinos. Devido à coleta indiscriminada, esta orquídea se apresenta ameaçada de extinção em Bangladesh, um de seus países de origem (BADRHA; BHOWMIK, 2005).

Em mercados internacionais, principalmente nos Estados Unidos, mudas dessa espécie são vendidas entre US\$ 7,00 a US\$ 15,00 (BARRIENTOS; ALFARO, 2002). No Brasil, o valor de mercado da planta florida varia de $\mathrm{R} \$ 10,00$, quando adquiridas diretamente do produtor, a $\mathrm{R} \$ 55,00$ quando compradas em floriculturas (TOMAZELA, 2006). Portanto, nacionalmente, tal planta também apresenta alto potencial mercantil, sendo apenas a melhoria das taxas de propagação da espécie uma das barreiras para o aumento de seu uso como ornamental, medicinal e sua ampla comercialização.

A semeadura in vitro é ferramenta para a propagação massal de espécies de orquídeas ameaçadas de extinção (SANTOS et al., 2006; PEDROSO-DEMORAES et al., 2009a; b). Entretanto, orquidicultores, por falta de conhecimento e indisponibilidade de informações em relação à nutrição destas plantas, empregam meios de cultivo complexos, com diversos nutrientes, vitaminas e reguladores de crescimento (VENTURA, 2002), elevando os custos desta forma de propagação (PEDROSO-DE-MORAES et al., 2009a; b).

Estudos in vitro realizados por Stancato et al. (2001) demonstram que a diminuição de custos é possível, somente pela simplificação dos meios de cultura atuais, onde as condições de cultivo são específicas para algumas espécies. Dessa forma, o presente trabalho teve por objetivo avaliar o crescimento de plântulas pós-germinação de Arundina graminifolia (D. Don) Hochr. em meio de cultura experimental MS (MURASHIGE; SKOOG, 1962) com metade da concentração de macronutrientes e em outros dois meios compostos pelos fertilizantes Hyponex ${ }^{\circledR}$ e Kristalon Laranja ${ }^{\circledR}$, em três diferentes níveis de $\mathrm{pH}$, durante um período de 180 dias de cultura in vitro, a fim de otimizar a produção de mudas dessa espécie.

\section{MATERIAL E MÉTODOS}

Para a realização do trabalho, cinco flores de plantas de genótipos diferentes da espécie Arundina graminifolia, cultivadas a céu aberto nos jardins do Centro Universitário Hermínio Ometto - UNIARARAS, Araras, São Paulo, foram 
autopolinizadas. Seis meses após a autopolinização, foram coletadas sementes dos frutos maturos, as quais foram homegeneizadas e levadas ao Laboratório de Botânica e Análises Ambientais da instituição, para o início do cultivo in vitro.

Foram preparados três tipos de meios de cultura, sendo o primeiro o meio MS (Murashige \& Skoog, 1962), modificado para conter metade da concentração de macronutrientes, o qual foi usado como controle, e os outros dois, por meios compostos pelos fertilizantes Hyponex ${ }^{\circledR}$ (NPK 6,5-6-19) e Kristalon Laranja ${ }^{\circledR}$ (NPK 6-12-36) a 2 g...-1 (Tabela 1).

Tabela 1. Formulação dos fertilizantes utilizados para o cultivo in vitro de Arundina graminifolia (D. Don) Hochr.

\begin{tabular}{cc|cc} 
Hyponex & & Kristalon Laranja & \\
Sais & $\%$ & Sais & $\%$ \\
Nitrato de potássio & 2 & Nitrato de potássio & 4,5 \\
Nitrato de amônio & 4,5 & Nitrato de amônio & 1,5 \\
Pentóxido de fósforo & 6 & Pentóxido de fósforo & 12 \\
Óxido de potássio & 19 & Óxido de potássio & 36 \\
Sulfato de magnésio & 2,5 & Sulfato de magnésio & 8 \\
Sulfato de zinco & 0,5 & Sulfato de zinco & 1,8 \\
Sulfato de cobre & 0,025 & Sulfato de cobre & 0,01 \\
Sulfato ferroso & - & Sulfato ferroso & 0,07 \\
Sulfato de manganês & 0,03 & Sulfato de manganês & 0,04 \\
Ácido bórico & 0,05 & Ácido bórico & 0,025 \\
Molibdato de sódio & 0,025 & Molibdato de sódio & 0,004 \\
\hline
\end{tabular}

Todos os meios de cultivo foram acrescidos de $1 \mathrm{~g} \mathrm{~L}^{-1}$ de carvão ativado, 30 $\mathrm{g} \mathrm{L}^{-1}$ de sacarose e tiveram seus $\mathrm{pH}$ ajustados para 5,3, 5,8 e 6,3 após a adição de $7 \mathrm{~g}$ $\mathrm{L}^{-1}$ de ágar-banana. Logo após, $50 \mathrm{~mL}$ de cada meio, com cada um dos níveis de $\mathrm{pH}$ foram vertidos em quatro frascos de $250 \mathrm{~mL}$ e esterilizados em autoclave a $121^{\circ} \mathrm{C}$ e 1 atm de pressão durante 20 minutos (ARDITTI; ERNEST, 1992).

As sementes foram desinfestadas por imersão em hipoclorito de sódio a $0,5 \%$, sendo submetidas à agitação na solução durante cinco minutos em tubos Eppendorf® (PEDROSO-DE-MORAES et al., 2009a; b). Posteriormente, os tubos foram mergulhados em álcool 70\% e levados à câmara de fluxo laminar, onde as 
sementes foram lavadas quatro vezes em água destilada autoclavada com o auxílio de seringa de $1 \mathrm{~mL}$, também autoclavada. Ainda utilizando-se de seringa estéril, as sementes, juntamente com $1 \mathrm{~mL}$ de água destilada autoclavada, foram depositadas nos frascos contendo os meios de cultura (ARDITTI; ERNEST, 1992). Foram semeados quatro frascos por tratamento, sendo inoculadas, por recipiente, $1 \mathrm{mg}$ de sementes. Os frascos semeados foram fechados com tampa plástica transparente e mantidos durante 180 dias em câmara climática (B.O.D. MA 403), à temperatura de $25 \pm 2$ ${ }^{\circ} \mathrm{C}$, sob fotoperíodo de 12 horas com intensidade luminosa de aproximadamente 40

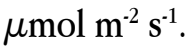

Para análise estatística, foram utilizados vinte indivíduos de cada frasco, retirados aleatoriamente dos meios de cultura (PEDROSO-DE-MORAES et al., 2009b; CUNHA et al., 2011). Foram auferidos os dados referentes à altura das plântulas (AP), comprimento da maior raiz (CMR), comprimento da maior folha (CMF), número de raízes (NR), massa da matéria fresca (PMF) e massa da matéria seca (PMS). Para a análise estatística dos dados foi utilizado o delineamento inteiramente casualizado (DIC) com quatro repetições, constituído em um esquema fatorial 3x3 (três meios de cultura $\mathrm{x}$ três níveis de $\mathrm{pH}$, em triplicata). A comparação entre as médias foi feita pelo teste de Tukey a 5\% de probabilidade. Para as avaliações, os dados foram transformados em Log visando à estabilização da variância e favorecimento da homogeneidade das amostras (SANTANA; RANAL, 2004).

\section{RESULTADOS E DISCUSSÃO}

Os resultados demonstraram que as plântulas de Arundina graminifolia, cultivadas em meio de cultura MS composto por metade da concentração de macro nutrientes e $\mathrm{pH}$ 5,8, apresentaram as maiores médias para todas as variáveis analisadas quando comparadas aos outros meios de cultivo associados aos demais níveis de $\mathrm{pH}$ (Tabela 2). Estes são corroborados pelos encontrados para a orquídea Epidendrum secundum, cultivada nos mesmos meios de cultura e potencial hidrogeniônico (MASSARO et al., 2012), e vão de encontro à afirmação de Rodríguez et al. (2005), de que mesmo o meio MS (MURASHIGE; SKOOG, 1962) tendo sido desenvolvido inicialmente para o uso em cultivo de tecido de tabaco, demonstra-se muito efetivo como substrato nutritivo para muitas espécies de orquídeas. 
Tabela 2. Médias obtidas para as variáveis: Número de raízes (NR), Altura das plântulas (AP), Comprimento da maior raiz (CMR), Comprimento da maior folha (CMF), Massa da matéria fresca (PMF) e Massa da matéria seca (PMS), de plântulas de Arundina graminifolia (D. Don.) Hochr., cultivadas em três diferentes meios de cultura e níveis de pH. CV (\%) = Coeficiente de variação

\begin{tabular}{|c|c|c|c|c|c|c|}
\hline \multirow{3}{*}{ Meio de cultivo } & \multicolumn{6}{|c|}{ pH } \\
\hline & 5,3 & 5,8 & 6,3 & 5,3 & 5,8 & 6,3 \\
\hline & \multicolumn{3}{|c|}{ NR } & \multicolumn{3}{|c|}{$\mathrm{AP}(\mathrm{cm})$} \\
\hline $1 / 2 \mathbf{M S}$ & $1,23 \mathrm{Ac}$ & $1,84 \mathrm{Aa}$ & $1,43 \mathrm{Ab}$ & $1,32 \mathrm{Ac}$ & $2,54 \mathrm{Aa}$ & $1,82 \mathrm{Ab}$ \\
\hline Hyponex & $1,21 \mathrm{Ac}$ & $1,50 \mathrm{Ba}$ & $1,33 \mathrm{Bb}$ & $1,19 \mathrm{Bc}$ & $1,90 \mathrm{Ba}$ & $1,54 \mathrm{Bb}$ \\
\hline Kristalon & $0,96 \mathrm{Bb}$ & $1,19 \mathrm{Ca}$ & $1,01 \mathrm{Cb}$ & $0,99 \mathrm{Cc}$ & $1,56 \mathrm{Ca}$ & $1,23 \mathrm{Cb}$ \\
\hline F - Mc & & $16,4^{*}$ & & & $13,6^{*}$ & \\
\hline $\mathbf{F} \cdot \mathbf{P h}$ & & $10,2^{* * *}$ & & & $9,2^{* *}$ & \\
\hline F - Mc x pH & & $10,5^{* *}$ & & & $9,9^{* *}$ & \\
\hline \multirow[t]{2}{*}{ CV (\%) } & & 4,8 & & & 3,1 & \\
\hline & \multicolumn{3}{|c|}{ CMR (cm) } & \multicolumn{3}{|c|}{ CMF (cm) } \\
\hline $1 / 2 \mathbf{M S}$ & $0,83 \mathrm{Ac}$ & $1,42 \mathrm{Aa}$ & $1,03 \mathrm{Ab}$ & $1,13 \mathrm{Ab}$ & $1,65 \mathrm{Aa}$ & $1,12 \mathrm{Ab}$ \\
\hline Hyponex & $0,33 \mathrm{Ab}$ & $0,87 \mathrm{Ba}$ & $0,85 \mathrm{Ba}$ & $1,01 \mathrm{Bb}$ & $1,20 \mathrm{Ba}$ & $1,04 \mathrm{Bb}$ \\
\hline Kristalon & $0,68 \mathrm{Ba}$ & $0,72 \mathrm{Ca}$ & $0,69 \mathrm{Ca}$ & $0,64 \mathrm{Cb}$ & $0,74 \mathrm{Ca}$ & $0,62 \mathrm{Cb}$ \\
\hline F - Mc & & $2,5^{* *}$ & & & $7,8^{* *}$ & \\
\hline F - pH & & $3,5^{*}$ & & & $5,9^{* *}$ & \\
\hline F - Mc x pH & & $1,5^{*}$ & & & $14,6^{*}$ & \\
\hline \multirow[t]{2}{*}{ CV (\%) } & & 2,26 & & & 9,35 & \\
\hline & \multicolumn{3}{|c|}{ PMF (g) } & \multicolumn{3}{|c|}{ PMS (g) } \\
\hline $1 / 2 \mathbf{M S}$ & $0,09 \mathrm{Ac}$ & $0,56 \mathrm{Aa}$ & $0,23 \mathrm{Ab}$ & $0,4 \mathrm{Ac}$ & $0,09 \mathrm{Aa}$ & $0,7 \mathrm{Ab}$ \\
\hline Hyponex & $0,06 \mathrm{Bb}$ & $0,25 \mathrm{Ba}$ & $0,24 \mathrm{Aa}$ & $0,3 \mathrm{Ab}$ & $0,07 \mathrm{Ba}$ & $0,4 \mathrm{Bb}$ \\
\hline Kristalon & $0,06 \mathrm{Bc}$ & $0,18 \mathrm{Ca}$ & $0,15 \mathrm{Bb}$ & $0,1 \mathrm{Bc}$ & $0,06 \mathrm{Ba}$ & $0,4 \mathrm{Bb}$ \\
\hline F - Mc & & $5,2^{* *}$ & & & $13,3^{*}$ & \\
\hline $\mathbf{F} \cdot \mathbf{p H}$ & & $2,8^{* * *}$ & & & $12,4^{*}$ & \\
\hline F - Mc x pH & & $1,2 * *$ & & & $14,2^{*}$ & \\
\hline CV (\%) & & 10,85 & & & 19,85 & \\
\hline
\end{tabular}

Médias seguidas por letras iguais não diferem entre si pelo teste de Tukey a $5 \%$ de probabilidade. Letras maiúsculas representam análise nas colunas e minúsculas nas linhas. *significativo a $p<0,05$; **significativo a $p<0,01$.

Reddy et al. (1992) avaliaram os meios de cultura MS, KC (KNUDSON, 1958), RL (ROSA; LANERI, 1977) e VW (VACIN; WENT, 1949), para germinação e 
desenvolvimento de plântulas de Cymbidium aloifolius, Dendrobium cripidatum e Epidendrum radicans, sendo que, assim como para todas as variáveis deste trabalho, o meio nutritivo MS apresentou os melhores resultados para desenvolvimento vegetativo das espécies analisadas. Também, para a orquídea rupestre Laelia cinnabarina, em trabalho desenvolvido com diferentes composições de meio de cultura, foram obtidos resultados satisfatórios no cultivo in vitro em meio MS com metade da concentração dos macronutrientes (STANCATO; FARIA, 1996).

Tais resultados em relação aos meios de cultura podem ser explicados pela presença de uma relação quadrática entre variáveis analisadas em plântulas submetidas a doses balanceadas de nitrogênio nítrico e amoniacal, em que se obtém principalmente o aumento de matéria seca e da altura de plântulas, como observado tanto para orquídeas terrestres do gênero Cymbidium quanto epífitas do gênero Cattleya (PEDROSO-DE-MORAES et al., 2009a; b). Da mesma forma, os resultados encontrados para os meios à base de fertilizantes para todas as variáveis estão de acordo com os encontrados para a bromélia Aechmea blanchetiana (KANASHIRO et al., 2007) e para a orquídea Cattleya loddigesii (PEDROSO-DE-MORAES et al., 2009a), nas quais o número de raízes decresceu linearmente com o aumento da concentração de nitrogênio nos meios de cultivo modificados.

A mesma tendência para a variável NR foi encontrada para Arundina graminifolia cultivada em meio de cultura MS suplementado com $15 \mathrm{~g} \mathrm{~L}^{-1}$ de sacarose (BHADRA; BHOWMIK, 2005), em que foi constatado maior número de raízes na concentração $50 \%$ de nitrato de amônio contido no meio MS e tendendo ao decréscimo nas maiores concentrações. Tal resultado leva à constatação de que as maiores percentagens de nitrogênio amoniacal encontradas nos fertilizantes Hyponex ${ }^{\circledR}$ e Kristalon Laranja ${ }^{\circledR}$, em comparação à do meio MS com metade da concentração de macronutrientes, podem ter sido as responsáveis pela melhor média apresentada para a variável, fato este corroborado pelos resultados obtidos em experimento com as orquídeas Cattleya loddigesii e C. tigrina, onde meios de cultivo à base dos mesmos fertilizantes foram analisados (PEDROSO-DE-MORAES et al., 2009a; b).

Para a orquídea epífita Oncidium baueri e para a terrestre Epidendrum secundum, as análises biométricas relativas à altura da parte aérea indicaram melhores 
resultados com a utilização do meio de cultura MS com metade da concentração de macronutrientes (SORACE et al., 2008; MASSARO et al., 2012), corroborando com os resultados encontrados neste trabalho para a variável altura das plântulas (AP) e para comprimento da maior folha (CMF). Além disso, para a orquídea Cattleya nobilior e para as bromélias Pitcairnia flammea e Vriesia philippocoburgii (MERCIER; KERBAUY, 1991; ARAÚJO et al., 2005) foi verificado que concentrações crescentes de amônio favoreceram o desenvolvimento do sistema radicular, o que concorda com os resultados referentes à variável analisada comprimento da maior raiz (CMR) obtida neste trabalho (Tabela 2).

Em relação aos demais macronutrientes que compõem os meios de cultura, deve-se ressaltar que a absorção de um dado nutriente pode ser influenciada por outro, sendo tal absorção altamente influenciada pelo $\mathrm{pH}$. Tal observação foi comprovada em bromélias, pela correlação linear existente entre o aumento nas concentrações de potássio e o consumo de nitrato por células vegetativas, promovendo um maior incremento nas características fitotécnicas (KANASHIRO et al., 2007). A combinação de $\mathrm{KCl}$ com $\mathrm{K}_{2} \mathrm{SO}_{4}$, ambos na concentração de $500 \mathrm{mg} \mathrm{L}^{-1}$, também promoveu maior crescimento in vitro em plântulas de Cattleya loddigesii, exceto para a variável comprimento da raiz, que apresentou melhores resultados com $500 \mathrm{mg} \mathrm{L}^{-1}$ de $\mathrm{KCl}$ na ausência de $\mathrm{K}_{2} \mathrm{SO}_{4}$ (FIGUEIREDO et al., 2008).

Em várias espécies de orquídeas a taxa de incorporação de íons fosfato depende do genótipo e da concentração de sais de potássio presentes no meio de cultivo, que é usualmente constante e proporcional à taxa de crescimento da cultura (CHEN et al., 2000). Dessa maneira, assim como exposto acima, em conjunto e da mesma forma que para o nitrogênio amoniacal, a maior concentração de sais fosfatados e sais contendo potássio no meio MS com metade da concentração de macronutrientes propiciaram incrementos nas variáveis biométricas analisadas principalmente em relação ao sistema radicular.

Nesse ínterim, os maiores índices de massa da matéria fresca e seca, e comprimento de plântulas pela utilização de meio de cultura contendo MS com metade da concentração de macronutrientes em comparação aos meios à base de fertilizantes NPK, para a orquídea epífita Catasetum fimbriatum e para a terrestre Epidendrum secundum (REGO-OLIVEIRA; FARIA, 2005; MASSARO et al., 2012), vem 
de encontro com os resultados encontrados para as mesmas variáveis analisadas neste trabalho (Tabela 2).

$\mathrm{O}$ efeito do $\mathrm{pH}$ nos meios nutritivos in vitro tem merecido atenção especial de pesquisadores por sua atuação direta sobre a disponibilidade de nutrientes neles contidos (CHAPLA et al., 2009). Orquídeas cultivadas assimbioticamente são extremamente sensíveis a mudanças em seus níveis normais de $\mathrm{pH}$, apresentando, em alguns casos, intolerância a variações da ordem de 0,05 , como no caso de representantes do gênero Encyclia, e tolerância em relação a maiores variações, até 1,5, como em plantas do gênero Cattleya (PEDROSO-DE-MORAES, 2000).

Segundo Arditti e Ernst (1984) a maior parte das espécies de orquídeas germina bem em pHs entre 4,8 e 5,2, com amplitude entre os pHs 3,6 e 7,6. Entretanto, Kämpf (2000) sugere que para um crescimento adequado da maioria das espécies de orquídeas, a faixa que revela o melhor ajuste é a de 5,0 a 6,5.

$\mathrm{O}$ processo de autoclavagem e a estocagem são fatores que acidificam os meios de cultura. Dessa forma, uma das maneiras de se impedir tal acidificação é a adição de carvão ativado, que estabiliza o $\mathrm{pH}$ do meio, serve de fonte alternativa de carbono para a cultura (PEDROSO-DE-MORAES, 2000) e pode ser benéfico em concentrações de 0,1 a $2 \%$, pois, fisicamente, simula a condição de escuro, na qual as raízes normalmente se desenvolvem melhor, tendo, devido a estes fatores, sido usado neste ensaio. Vários são os relatos na literatura que comprovam os benefícios do uso do carvão ativado para a cultura in vitro de orquídeas, principalmente levando-se em consideração dados biométricos (MORALES et al., 2006; MURDAD et al., 2006; CHAPLA et al., 2009). Entretanto, mesmo com o uso do carvão ativado, os meios de cultura ainda se alteram em relação à acidez devido ao crescimento celular (MURDAD et al., 2006). $\mathrm{O}$ pH de meios de cultura se modifica à medida que diferentes íons são absorvidos e os produtos metabólicos são excretados para o meio, fato este principalmente causado pela absorção diferencial do amônio e do nitrato (MURDAD et al., 2006).

Neste trabalho, os meios com $\mathrm{pH}$ ajustados para 6,3 assumiram valores intermediários para as variáveis analisadas, o que corrobora com os resultados obtidos para a orquídea epífita Baptistonia pubes cultivada em meio MS modificado e em meio à base de banana nanica acrescido de fertilizante NPK 20-20-20 Plant 
Prood $^{\circledR}(\mathrm{BAN})$, com pH ajudado para 6,2 (FERREIRA et al., 2010). Já o nível de pH 5,3 pode ser considerado o pior para todos os meios de cultura usados, mesmo existindo uma tendência das orquídeas terrestres germinarem em faixa de pHs mais baixos que as epífitas (DIEZ, 2007), afirmação esta discordante dos resultados obtidos para Baptistonia pubes, em que os maiores valores para as variáveis analisadas foram obtidos para os meios ajustados para 5,2 (FERREIRA et al., 2010).

$\mathrm{O}$ ajuste de $\mathrm{pH}$ dos meios de cultivos usados para 5,8 obteve os melhores resultados para todas as variáveis quantitativas e biométricas analisadas, o que corrobora com trabalhos recentes enfocando germinação e regeneração in vitro de representantes da família, sejam eles terrestres, litófitos ou epífitos, os quais apresentam meios de cultivo ajustados para este nível de pH (ARAÚJO et al., 2009; CHAPLA et al., 2009; PEDROSO-DE-MORAES et al., 2009a; b; SUZUKI et al., 2009; BESSON et al., 2010; GALES et al., 2010; SCHEIDT et al., 2010; SOARES et al., 2010; SOUTO et al., 2010; CHIU et al., 2011; CUNHA et al., 2011; KEEL et al., 2011; LIAU et al., 2011; ROY et al., 2011), com exceção dos geralmente utilizados para cultivo de orquídeas do gênero Phalaenopsis e Dendrodium, para os quais são encontrados, em geral, os níveis de 5,4 e 6,0 respectivamente (CHEN et al., 2000; MURDAD et al., 2006; PEDROSO-DE-MORAES et al., 2010).

\section{CONCLUSÃO}

O meio de cultivo MS com metade da concentração de macronutrientes ajustado para $\mathrm{pH}$ 5,8 demonstrou ser o mais eficaz no crescimento in vitro de plântulas de Arundina graminifolia como demonstrado para todas as variáveis analisadas, em detrimento dos meios de cultivo à base dos fertilizantes Hyponex® e Kristalon Laranja ${ }^{\circledR}$. A obtenção de tais resultados aponta para a necessidade de mais investigações em relação ao uso de fertilizantes como base de meios de cultura para propagação in vitro da espécie, uma vez que para outras orquídeas, o uso de fertilizantes constitui eficiente forma de redução de custos de produção. 


\section{REFERÊNCIAS}

ACHARYA, K. P.; ROKAYA, M. B. Medicinal Orchids of Nepal: Are They Well Protected? Our Nature, v. 8, n. 1, p. 82-91, 2010.

ARAÚJO, A. G. et al. Meios de cultura e $\mathrm{GA}_{3}$ no cultivo in vitro de um híbrido de orquídea. Horticultura Brasileira, Suplemento, p. 612-615, 2005.

ARAÚJO, A. G. et al. Fontes de nitrogênio no crescimento in vitro de plântulas de Cattleya loddigesii Lindl. (Orchidaceae). Acta Scientiarum. Biological Sciences, v. 31, n. 1, p. 35-39, 2009.

ARDITTI, J.; ERNST, R. Physiology of germinating orchid seeds. In: Arditti, J. (ed.). Orchid biology: reviews and perspectives III. New York: Cornell University Press, 1984. p. 177-222.

ARDITTI, J.; ERNST, R. Micropropagation of orchids. New York: John Wiley \& Sons, 1992. 682p.

BARRIENTOS, J. M.; ALFARO, L. M. Efecto del efluente de excretas de bovinos sobre el crecimiento inicial de la orquídea Arundina graminifolia (D. Don.) Hochr. InterSedes, v. 3, n. 4, p. 45-51, 2002.

BESSON, J. C. F. et al. Fontes e concentrações de carboidratos no crescimento vegetativo e no enraizamento in vitro de Miltonia flavescens Lindl. Revista Brasileira de Biociências, v. 8, n. 1, p. 9-13, 2010.

BHADRA, S. K. et al. Micropropagation of Dendrobium apbyllum (Roxb.) G. E. C. Fisher. Bangladesh J. Genetics and Biotechnology, v. 3, n. 2, p. 47-50, 2002.

BHADRA, S. K.; BHOWMIK, T. K. Axenic germination of seeds and rhizome-based micropropagation of an orchid Arundina graminifolia (D. Don.) Hochr. Bangladesh Journal of Botany, v. 34, n. 2, p. 59-64, 2005.

CHAPLA, P. I. et al. pH, carvão ativado e agentes geleificantes do meio de cultura no crescimento in vitro de Miltonia flavescens Lindl. Plant Cell Culture \& Micropropagation, v. 5, n. 2, p. 87-93, 2009. 
CHEN, Y.; CHANG, C.; CHANG, W. A reliable protocol for plant regeneration from callus culture of Phalaenopsis. In Vitro Cellular and Developmental Biology Plant, v. 36, n. 3, p. 420-423, 2000.

CHIU, Y-T.; LIN, C-S.; CHANG, C. In vitro fruiting and seed production in Erycina pusilla (L.) N. H. Williams \& M. W. Chase. Propagation of Ornamental Plants, v. 11, n. 3, p. 131-136, 2011.

CUNHA, T. et al. Desenvolvimento in vitro de Laeliocattleya schilleriana Rolfe em meios de cultivo simplificados. Scientia Plena, v. 7, n. 8, p. 1-5, 2011.

DIEZ, J. M. Hierarchical patterns of symbiotic orchid germination linked to adult proximity and environmental gradients. Journal of Ecolog y, v. 95, n. 1, p. 159-170, 2007.

FERREIRA, A. W. C. et al. Propagação in vitro de Baptistonia pubes (Lindl.) Chiron \& V. P. Castro (Oncidium pubes Lindl.) (Orchidaceae). Acta Botanica Brasilica, v. 24, n. 3, p. 636-639, 2010.

FIGUEIREDO, A. M. et al. Fontes de potássio no crescimento in vitro de plantas de orquídea Cattleya loddigesii. Ciência Rural, v. 4, n. 1, p. 255-257, 2008.

GALE, S. W. et al. Constraints on establishment in an endangered terrestrial orchid: a comparative study of in vitro and in situ seed germinability and seedling development in Nervilia nipponica. Botanical Journal of the Linnean Society, v. 163 , n. 2, p. 166-180, 2010.

KÄMPF, A. N. Produção comercial de plantas ornamentais. Porto Alegre: Ed. Guaíba, 2000. 254p.

KANASHIRO, S. et al. Efeitos de diferentes concentrações de nitrogênio no crescimento de Aechmea blanchteana (Baker) L. B. Sm. cultivada in vitro. Hoehnea, v. 34, n. 2, p. 59-66, 2007.

KEEL, B. G.; ZETTLER, L. W.; KAPLIN, B. A. Seed Germination of Habenaria repens (Orchidaceae) in situ Beyond its Range, and its Potential for Assisted Migration Imposed by Climate Change. Castanea, v. 76, n. 1, p. 43-54, 2011. 
KNUDSON, L. A new nutrient solution for germination of orchid seed. American Orchid Society Bulletin, v. 15, n. 2, p. 214-217, 1946.

LIAO, Y-J. et al. In vitro shoot induction and plant regeneration from flower buds in Paphiopedilum orchids. In Vitro Celular \& Developmental Biolog y - Plant, v. 47, n. 6, p. 702-709, 2011.

LORENZI, H.; SOUZA, H. M. Plantas ornamentais no Brasil: arbustivas, herbáceas e trepadeiras. Nova Odessa: Instituto Plantarum, 1999. 1120p.

MASSARO, R. et al. Avaliação do desenvolvimento in vitro de Epidendrum secundum Jacq. em meios de cultivo simplificados. Rama: Revista em Agronegócio e Meio Ambiente, v. 5, n. 2, p. 337-351, 2012.

MEDHI, R. P.; CHAKRABARTI, S. Traditional Knowledge of NE people on conservation of wild orchids. Indian Journal of Traditional Knowledge (IJTK), v. 8, n. 1, p. 1116, 2009.

MERCIER, H.; KERBAUY, G. B. Effects of nitrogen source on growth rates and levels of endogenous cytokinins and chlorophyll in protocorms of Epidendrum fulgens. Journal of Plant Physiology, v. 138, n. 2, p. 195-199, 1991.

MORALES, S.; MILANEZE, M. A. G.; MACHADO, M. F. P. S. Effect of activated charcoal for seedlings development of Catasetum fimbriatum Lindl (Orchidaceae). Journal of Plant Sciences, v. 1, n. 4, p. 388-391, 2006.

MURASHIGE, T.; SKOOG, F. A revised medium for rapid growth and bio-assays with tobacco tissue cultures. Physiologia Plantarum, v. 15, n. 2, p. 473-497, 1962.

MURDAD, R. et al. High multiplication of Pbalaenopsis gigantea using trimmed bases protocorms technique. Scientia Horticulturae, v. 111, n. 3, p. 73-79, 2006.

PEDROSO-DE-MORAES, C. Cultivo de Orquídeas. Araras: Biblioteca Duse Rüegger Ometto, 2000. 145p. 
PEDROSO-DE-MORAES, C. et al. Desenvolvimento in vitro de Cattleya loddigesii Lindley (Orchidaceae) utilizando fertilizantes comerciais. Revista Brasileira de Biociências, v. 7, n. 1, p. 67-69, 2009a.

PEDROSO-DE-MORAES, C. et al. Desenvolvimento in vitro de Cattleya tigrina A. Richard (Orchidaceae) utilizando fertilizantes comerciais. Ensaios e Ciência, v. 13, n. 3, p. 57-65, 2009b.

PEDROSO-DE-MORAES, C. et al. Desenvolvimento in vitro de Dendrobium nobile Lind. (Orchidaceae) em recipientes de diferentes volumes. Revista Brasileira de Biociências, v. 8, n. 2, p. 255-258, 2010.

PEDROSO-DE-MORAES, C. et al. Response of Cattleya hybrids for Fusarium oxysporum f. sp. cattleyae Foster. Brazilian Archives of Biology and Technology, v. 54, n. 2, p. 267-271, 2011.

REDDY, P. V.; NANJAN, K.; SHANMUGAVELU, K. G. In vitro studies in tropical orchids: seed germination and seedling growth. Coimbatori, v. 6, n. 1-2, p. 75-78, 1992.

REGO-OLIVEIRA, L. V.; FARIA, R. T. In vitro propagation of Brazilian orchids using traditional culture media and commercial fertilizers formulations. Acta Scientiarum Agronomy, v. 27, n. 1, p. 1-5, 2005.

RODRÍGUEZ, L. et al. Producción y recuperación de orquídeas silvestres cubanas. v. 1, p. 4-9, 2005. Disponível em: < http://www.secretariadeambientegov. co/sda/libreria/pdf/ecosistemas/restauracion/1_ar26.pdf> Acesso em: 22 dez. 2011.

ROSA, M. D.; LANERI, U. Modification of nutrient solutions for germination and growth in vitro of some cultivated orchids and the vegetative propagation of Cymbidium cultivars. American Orchid Society Bulletin, v. 46, n. 9, p. 813-820, 1977.

ROY, A. R. et al. Asymbiotic seed germination, mass propagation and seedling development of Vanda coerulea Griff ex.Lindl. (Blue Vanda): An in vitro protocol for an endangered orchid. Scientia Horticulturae, v. 128, n. 3, p. 325-331, 2011. 
SANTANA, D. G.; RANAL, M. A. Análise da Germinação: um enfoque estatístico. Brasília: Universidade de Brasília, 2004. 248p.

SANTOS, A. F. et al. Otimização da propagação de Sophronitis coccinea (Orchidaceae) considerando meios de cultivo com adição de carvão ativado. Horta, v. 46, n. 3, p. $8-12,2006$.

SCHEIDT, G. N. et al. Multiplicação in vitro de Oncidium leucochilum (Orchidaceae) em diferentes sistemas de cultivo. Biociências, v. 17, n. 1, p. 82-85, 2010.

SIGH, A.; DUGGAL, S. Medicinal Orchids: An Overview. Ethnobotanical Leaflets, v. 13, n. 1, p. 399-412, 2009.

SOARES, J. D. R. et al. Estiolamento e luz artificial no cultivo in vitro de orquídeas nativa e híbrida. Ciência Rural, v. 40, n. 9, p. 1941-1947, 2010.

SORACE, M. et al. Crescimento in vitro de Oncidium baueri (Orchidaceae) em diferentes concentrações de macronutrientes e sacarose. Semina: Ciências Agrárias, v. 29, n. 4, p. 775-782, 2008.

SOUTO, J. S. et al. Efeitos do ácido naftalenoacético no desenvolvimento in vitro de Cattleya bicolor Lindl. (Orchidaceae). Revista Brasileira de Biociências, v. 8, n. 2, p. 179-185, 2010.

STANCATO, G. C.; Bemelmans, P. F.; VEGRO, C. L. R. Produção de mudas de orquídeas a partir de sementes in vitro e sua viabilidade econômica: estudo de caso. Revista Brasileira de Horticultura Ornamental, v. 7, n. 1, p. 25-33, 2001.

STANCATO, G. C.; FARIA, R. T. In vitro growth and mineral nutrition of the lithophytic orchid Laelia cinnabarina Batem (Orchidaceae): effects of macro and microelements. Lindleyana, v. 11, n. 1, p. 41-43, 1996.

SUZUKI, R. M. et al. Estudo da germinação e crescimento in vitro de Hadrolaelia tenebrosa (Rolfe) Chiron \& V. P. Castro (Orchidaceae), uma espécie da flora brasileira ameaçada de extinção. Hoehnea, v. 36, n. 4, p. 657-666, 2009. 
TOMAZELA, J. M. Orquídeas em Meio a Bananais. Suplemento Agrícola. O Estado de São Paulo, n. 2665, p. 6-7, 2006.

VACIN, E. F.; WENT, F. W. Some pH changes in nutrient solutions. Botanical Gazette, v. 110, n. 4 , p. 604-613, 1949.

VENTURA, G. M. et al. Organogênese in vitro a partir de gemas apicais e axilares de plantas adultas de orquídeas do grupo Cattleya. Revista Ceres, v. 47, n. 286, p. 613-628, 2002.

Recebido em: 23 de maio de 2014 Aceito em: 21 de maio de 2015 